\title{
Analgesic and Anti-inflammatory Activities of N-buthanol Portion of Acacia nilotica Pods in Mice and Wistar rats
}

\author{
${ }^{*}{ }^{2}$ Maibouge Tanko Mahamane Salissou, ${ }^{1}$ Yusuf. Tanko, ${ }^{3}$ Abdullahi Hamza Yaro, ${ }^{1}$ Rabiu \\ AbduSSALAM Magaji \\ ${ }^{1}$ Department of Human Physiology, Faculty of Medicine Ahmadu Bello University, Zaria, Nigeria \\ ${ }^{2}$ College of Health; Natural and Agriculture Sciences Africa University, Mutare, Zimbabwe \\ ${ }^{3}$ Department of Pharmacology Faculty of pharmaceutical science Bayaro University Kano Nigeria.
}

\begin{abstract}
Background: Acacia nilotica (AN) has diverse ethno medicinal uses: rheumatic pain, and inflammation. Unexpected side effects of analgesic, steroidal drugs and NSAIDs are reported in several studies, leading to continuous search of plants and their active fraction for management of pain and inflammatory disorders. The aim of study is to investigate its active fraction using pods in view of characterization of its active ingredients, to carry out phytochemical screening, acute toxicity study, evaluate central, peripheral analgesic effect and anti-inflammatory activities. Acute toxicity study was done by methods of Lorke 1983 phytochemical screening was done using standard methods, peripheral analgesic effect was evaluated using acetic acid induced writhing test, central analgesic activity using hot plat method while the anti-inflammatory activity of the extract was done using formalin induced hind paw edema model

Results: Phytochemical screening, revealed presence of flavonoids, tannin, saponnin, glycosides , the acute toxicity studies showed an LD 50 of $565 \mathrm{mg} / \mathrm{kg}$ (ip). The fraction showed both central and peripheral analgesic activity. In the acetic acid-induced writhing test for peripheral analgesic activity, BF ANP at the $160,80,40 \mathrm{mg} / \mathrm{kg}$ dose inhibits writhing, comparable to ketoprofen $(10 \mathrm{mg} / \mathrm{kg}) \quad(\mathrm{P} \leq 0.001)$. Using hot plat method, BF ANP produced central analgesic activity in a dose-dependent manner when compared to pentazocine. Both BF ANP and pentazocine inhibit significantly licking activity in the formalin-induced pain in mice. BF ANP produced a significant reduction in carrageenan-induced paw edema $(\mathrm{p} \leq 0.05)$. BF ANP when compare to standard drugs ketoprofen is as potent as standard drugs.

Conclusion BF ANP possesses anti-inflammatory and both central and peripheral analgesic activity due to presence of flavonoids tannin and saponin. Also these finding indicated at high doses the BFANP is more potent than the known standards drugs namely pentazocine and ibuprofen, however caution should be the high toxicity found in this study of BF.ANP.
\end{abstract}

Keywords: Acacia nilotica pods, acetic acid, carrageenan, edema, analgesic activity, anti-inflammatory activity

\section{Background}

Pain is an unpleasant sensory and emotional experience and is correlated with actual or potential tissue damages, or described in terms of such damages. (Kumar et al; 2016). Pain is triggered by noxious stimuli and transmitted over specialized neuronal networks to the CNS where it is interpreted as such. Pain sensation involved both the peripheral nociceptive and central mechanisms in the CNS and spinal cords. Pain is viewed as a protective mechanism for the body from possible injury (Stanton et al; 1995). Inflammation is a response of vascularized tissue to damage due to physical trauma, noxious chemicals, and microbial agents'.It is viewed as a harmful reaction, however, it is a protective response that is essential for survival. It serves to rid the host of both the initial cause of cell injury and the consequences of such injury (Kumar; 2017). Several strategies have been used in the prevention of chronic inflammatory diseases including suppression of the over-expressed pro-inflammatory mediators through the usage of NSAIDs 
drugs (Yoon et al; 2009). Despite the availability of sufficient drugs, pain and inflammation are still the most challenging and global burden health problems which affect $80 \%$ of the adult population worldwide (WHO; 2012). Untreated and persistently prolonged pain can give rise to damage and psychological disorders (Henschke et al 2015). Non-resolving inflammation results in the progression of serious inflammatory diseases, including asthma, and others autoimmune diseases. The currently available standard drugs for pain and inflammation remain the mainstay for managing and treating these disorders however, they are associated with many side effects and toxicities (Tamrat et al 2017). Furthermore, opioid analgesics are associated with several unwanted side effects and toxicities, including, addiction, and respiratory problems. Given these, there is a need for continuous research into medicinal plants and their active portion and principles which are claimed to be effective in the management of pain and inflammation (Schug et al 2003).

Acacia Nilotica is a plant commonly found in India, Pakistan, and many countries in Africa. The whole plant species are distributed in subtropical, tropical, from Egypt to Mauritania, Southward to South Africa and Asia, Eastward to India. In Nigeria and the Niger Republic, the plant is known in Hausa as Bagarua.

In traditional medicine different types of Acacia nilotica preparations are used for a variety of diseases including sore throat, gingivitis, colitis, diarrhea, bleeding, diabetes, skin diseases, cancer, toothaches, and inflammation of the oral cavity. Aqueous infusions of the seed pods or bark of the plant have been used in folk medicine for gastrointestinal disorders, while pulverized seeds and pods are used to hasten cicatrization of syphilitic ulcers. In Burkina Faso, Acacia nilotica (adansonii) is widely used in folk medicine during lactation (Lompo-Ouedraogo et al, 2004). There was preliminary work carried by (Dafallah and AlMustapha 1996) shown the potential analgesic and anti-inflammatory activity of the plant, therefore this work is carried out to determine the active fraction using the pods of the plant since according to an estimate made by the World Health Organization (WHO), around $80 \%$ of the world population in developing countries depend on traditional plants medicines for their primary health care needs, of which a majority involves the use of plant extracts or their active fractions (Aiyelero et al.,2009). The study is aimed at assessing acute toxicity; phytochemical screening; the analgesic and anti-inflammatory activities of $\mathrm{N}$ buthanol portion of Acacia Nilotica pods in mice and Wistar rats through acetic acid-induced writing; hot plat tests for analgesics; formalin and carrageenan paw edema for anti-inflammatory activity detection

\section{Main Text}

\section{0. Materials and Methods}

This study was conducted in the Department of pharmacology and therapeutic Faculty of Pharmaceutical Sciences Ahmadu Bello University Zaria, Kaduna state, Nigeria.

\subsection{Plant material:}

The pods of Acacia nilotica were obtained from Niger Republic (Maradi State) around April.2010. The botanical identification and authentication of the plant were carried out at the herbarium section of the Department of Biological Sciences Ahmadu Bello University, Zaria with Identification number :(v/no 698).

\subsection{Experimental animals}

A total of 133 animals: Seventy-three (73) Adult Swiss albino mice and Sixty (60) rats of both sexes were used for the experiments. The animals were maintained under normal laboratory conditions of humidity, temperature, and light for 7 days before the experiment, and allowed free access to food and water $a d$ Libitum.

\subsection{Methods}

\subsubsection{Preparation of the extract}

The extraction was carried out at the Department of Pharmacognosy, Faculty of Pharmaceutical Sciences Ahmadu Bello University Zaria. The pods were dried under shade for five days, then pounded and grounded into a fine powder using mortar and pestle. The powdered material was macerated in distilled water at room temperature for $24 \mathrm{~h}$. It is then filtered using filter paper (Whatmann size 1). The filtrate was then be 
partitioned with Ethyl acetate then with n-Butanol to get an n-Butanol fraction which was evaporated to dryness in an oven at $40^{\circ} \mathrm{C}$ which give the yield of $19 \mathrm{gm}$ that have a coffee-like color and kept in a sealed container at $4^{\circ} \mathrm{C}$ in a refrigerator until use.

\subsubsection{Phytochemical screening}

The extract was subjected to preliminary phytochemical screening tests for the presence of carbohydrate, flavonoids, alkaloids, saponins, tannins, and glycosides according to the method described by Trease and Evans (1983).

\subsubsection{Acute Toxicity Studies}

The intraperitoneal LD50 of the extract in mice is conducted according to the method of Lorke (1983). In the initial phase, 3 groups of three mice each are treated with the fraction (BF ANP) at doses of 10, 100, and $1000 \mathrm{mg} / \mathrm{kg}$ body weight i.p. and observed for signs of toxicity and death for 24 hours. In the second phase, 4 groups each containing one mouse was injected intraperitoneally with four more specific doses of the $\mathrm{BF}$ ANP based on the result of the first phase. The LD50 is calculated as the square root of the product of the lowest lethal dose and the highest non-lethal dose, i.e. the geometric mean of the consecutive doses in which 0 and $100 \%$ survival rates were recorded.

\subsection{Experimental Design}

Hot-plate test: The 'hot-plate (thermal) analgesic test method described by Turner (1965) was used for this study. A $600 \mathrm{ml}$ glass beaker was placed on a hot plate (with adjustable temperature). The temperature of the hot plate will be regulated to $45^{\circ} \mathrm{C}\left( \pm 1^{0} \mathrm{C}\right)$. Thirty mice were divided into five groups of six animals per group. Groups 1 had received normal saline $(1 \mathrm{ml} / \mathrm{kg}$, oral), groups $2-4$ were treated with doses of the plant portion: $40,80,160 \mathrm{mg} / \mathrm{kg} \mathrm{b}$ w (i.p). The 5 th group was treated with Pentazocine $(10 \mathrm{mg} / \mathrm{kg}$, i.p.). After 30 minutes, the animals were placed on the hot plate. The reaction time (i.e. time taken by the animal to leak the paw or jump out of the beaker), in seconds, was taken for each animal and repeated four times at 30 minutes intervals. The reaction time was noted and recorded in seconds. The percentage thermal pain inhibition or protection was calculated using the formula:

$\%$ protection against thermal pain $=\underline{(\text { Control mean }- \text { test mean })} \times 100$

Control means

Acetic acid-induced writhing in mice: The method described by Koster et al., (1959) and Taber et al., (1969) was used. Thirty mice were divided into five groups of six animals per group. Groups 1 have received normal saline $(1 \mathrm{ml} / \mathrm{kg}$, oral), groups $2-4$ had received three different doses of buthanol portion of the plant, 40, 80,160mg/kg i.p. The 5th group was treated with ketoprofen $(10 \mathrm{mg} / \mathrm{kg}$, i.p.). After 30 minutes, $1 \%$ acetic acid solution $(0.1 \mathrm{ml} / \mathrm{kg}$ ) was injected intraperitoneally to all groups. The writhes (each of which is characterized by a wave of contraction of abdominal musculature followed by extension of the hind limbs) were counted 5 minutes after acetic acid injection for 10 minutes.

Formalin test in rats: Thirty rats were divided into 5 groups each containing six rats. Group 1 was given normal saline ( $1 \mathrm{ml} / \mathrm{kg}$, i.p.). Groups 2-4 were treated with $40,80,160 \mathrm{mg} / \mathrm{kg} \mathrm{b}$ w doses of butanol portion of the plant. The 5 th group was treated with pentazocine $10 \mathrm{mg} / \mathrm{kg}$. Thirty minutes after this treatment; $50 \mu \mathrm{l}$ of a freshly prepared $2.5 \%$ solution of formalin was injected subcutaneously under the plantar surface of the left hind paw of each rat. The rats were placed individually in an observation chamber and monitored for one hour. The severity of pain response was recorded for each rat based on the following scale: (0) rat walk or stand firmly on the injected paw; (1) the injected paw is favored or partially elevated; (2) the injected paw is lifted off the floor; (3) the rat lick, chew or shake the injected paw (Yerima et al., 2009).

Carrageenan induced paw edema: Thirty rats were divided into 5 groups of six rats each. Group 1 was given normal saline $(1 \mathrm{ml} / \mathrm{kg})$ orally. The buthanol portion of the plant was administered to groups 2-4.at the doses of $40,80,160 \mathrm{mg} / \mathrm{kg}$. The 5 th group was treated with Ketoprofen $(10 \mathrm{mg} / \mathrm{kg}$, i.p.). Acute inflammation of the hind paw was induced in each of the rats by injecting a freshly prepared $0.1 \mathrm{ml}$ of $1 \% \mathrm{w} / \mathrm{v}$ suspension of carrageenan in saline solution into the sub-plantar surface of the right hind paw. The diameter of the 
injected paw is measured (with a vernier caliper) for $4 \mathrm{~h}$ at 1 -hour intervals. An increase in the diameter of the right hind paws is taken as an indicator of paw edema. Edema is assessed in terms of the difference in the 'zero time' $(C \mathrm{C})$ diameter of the injected right hind paw, and its diameter at 'time t' $[(C \mathrm{t})$ - i.e. $1,2,3,4$ hours,] following carrageenan administration. The increases in the right hind paw diameters induced by injections of carrageenan are compared with those of the contralateral, non-injected left hind paw diameters (Ojewole, 2006).

Inhibition $(\%)=\underline{\text { Mean paw diameter (control) - Mean paw diameter (treated) }} \times 100$

Mean paw diameter (control)

\subsection{Statistical analysis}

Data obtained from the experiments are analyzed and expressed as means $( \pm$ SEM). The differences between the plant extract, drug-treated 'test' mice or rats means, and normal saline-treated 'control' mice or rats means are analyzed statistically by student's t-test, followed by one-way analysis of variance (ANOVA; $95 \%$ confidence interval). Values of $\mathrm{p} \leq 0.05$ are taken to imply statistical significance.

\section{Results}

\subsection{Phytochemical screening of BFANP}

Phytochemical screening of fractionated plants revealed the presence of carbohydrates, glycosides, anthraquinones, cardiac glycosides, saponins, steroids, flavonoids, and Tannins as shown in table 1.

Table 1: Phytochemical screening of BFANP.

\begin{tabular}{|l|l|}
\hline CONSTITUENT & INFERENCE \\
\hline Carbohydrates & + \\
\hline Glycosides & + \\
\hline Anthraquinones & + \\
\hline Cardiac glycosides & + \\
\hline Saponins & + \\
\hline Steroids & + \\
\hline Flavonoids & + \\
\hline Tannins & + \\
\hline Alkaloids & - \\
\hline Combines Anthracenes & - \\
\hline
\end{tabular}

Key: + Presence

- Absence

\subsection{Acute toxicity studies of BF-ANP}

From the data collected in this study, the median lethal dose $\left(\mathrm{LD}_{50}\right)$ of $\mathrm{n}$-buthanol fraction of Acacia nilotica pods in mice was calculated as the square root of the product of the lowest lethal dose and the highest nonlethal dose, i.e. the geometric mean of the consecutive doses with 0 and $100 \%$ survival. The final Intraperitoneal $\mathrm{LD}_{50}$ in mice is $\mathrm{V} 400 \mathrm{X} 800=565.7 \mathrm{mg} / \mathrm{kg} \mathrm{b} \mathrm{w}$ (IP).

\subsection{Acetic acid-induced writhing.}

The n-buthanol fraction of Acacia nilotica pods (BF ANP) administration at $160,80,40 \mathrm{mg} / \mathrm{kg}$ significantly $(p \leq 0.001)$ inhibits the numbers of writhing and stretching produced by IP injection of $0.6 \%$ acetic acid. The 
reference drug ketoprofen $(10 \mathrm{mg} / \mathrm{kg})$ also produced significant protective effects against acetic acidinduced pain. $(\mathrm{P} \leq 0.001)$. The percentage inhibition of pain was calculated to be $94.4 \% 71.7 \%, 79.1 \%$ at the dose of $160,80,40 \mathrm{mg} / \mathrm{kg}$ respectively and this was low compare to standard drugs $95.5 \%$ as shown in table 2.

Table 2 Effect of BF ANP and Ketoprofen on Acetic acid-induced writhing in mice

\begin{tabular}{|l|c|c|c|}
\hline Treatment & Dose $(\mathbf{m g} / \mathbf{k g})$ & $\begin{array}{c}\text { Mean No. of } \\
\text { writhes per 10 min }\end{array}$ & $\begin{array}{c}\text { Percentage } \\
\text { inhibition }\end{array}$ \\
\hline Normal Saline & & 17.7 & \\
\hline BF.ANP & $160 \mathrm{mg} / \mathrm{kg}$ & $2.3 \pm 0.4^{\mathrm{C}}$ & 94.4 \\
\hline B.F ANP & $80 \mathrm{mg} / \mathrm{kg}$ & $5 \pm 1.2^{\mathrm{C}}$ & 71.7 \\
\hline BF ANP & $40 \mathrm{mg} / \mathrm{kg}$ & $3.7 \pm 0.8^{\mathrm{C}}$ & 79.1 \\
\hline (ketoprofen) & $10 \mathrm{mg} / \mathrm{kg}$ & $0.8 \pm 0.4^{\mathrm{C}}$ & 95.5 \\
\hline
\end{tabular}

C: represent $\mathrm{P} \leq 0.001$. (b) Represent $\mathrm{P} \leq 0.01$. (a) Represent $\mathrm{P} \leq 0$.05.student t-test $\mathrm{n}=6$

. Values represent mean \pm S.E.M

\subsection{Formalin test in rats.}

Both the BF ANP $(160,80,40 \mathrm{mg} / \mathrm{kg})$ and standard drugs pentazocine (IP) inhibit significantly $(\mathrm{p} \leq 0.001)$ the licking activity in the first phase of the formalin-induced pain in mice. In phase two: $160 \mathrm{mg} / \mathrm{kg}$ dose and standard drugs inhibit significantly $(\mathrm{p} \leq 0.001)$ while $80,40 \mathrm{mg} / \mathrm{kg}$ inhibit by $\mathrm{P} \leq 0.01)$, the reference antinociceptive drug pentazocine $(10 \mathrm{mg} / \mathrm{kg}$,) significantly inhibited the licking activity against both phases of formalin-induced nociception $(\mathrm{p} \leq 0.001)$ as shown in table 3 .

Table 3 Effect of BF ANP on Formalin test in mice

\begin{tabular}{|l|c|c|c|}
\hline Groups & $\begin{array}{c}\text { Dose } \\
(\mathbf{m g} / \mathbf{k g})\end{array}$ & \multicolumn{2}{|c|}{ Mean pain score \pm SEM } \\
\hline & & First phase & $\begin{array}{c}\text { Second } \\
\text { phase }\end{array}$ \\
\hline $\begin{array}{l}\text { (Normal } \\
\text { Saline) }\end{array}$ & - & $2.83 \pm 0.16$ & $2.17 \pm 0.16$ \\
\hline BF ANP & 160 & $1.33 \pm 0.2^{\mathrm{c}}$ & $0.33 \pm 0.2^{\mathrm{c}}$ \\
\hline BF ANP & 80 & $1.5 \pm 0.22^{\mathrm{c}}$ & $1.33 \pm 0.2^{\mathrm{b}}$ \\
\hline BF ANP & 40 & $1.5 \pm 0.22^{\mathrm{c}}$ & $1.33 \pm 0.2^{\mathrm{b}}$ \\
& & & \\
\hline
\end{tabular}




\begin{tabular}{|c|c|c|c|}
\hline Pentazocine & 10 & $1.67 \pm 0.2^{\mathrm{c}}$ & $0.67 \pm 0.2^{\mathrm{c}}$ \\
\hline
\end{tabular}

\subsection{Carrageenan induced paw edema}

The BF ANP produced a significant effect on reducing carrageenan-induced paw edema $(\mathrm{p} \leq 0.05)$ at the dose of $160,80,40 \mathrm{mg} / \mathrm{kg}$ in all 1,2,3,4 hours post-treatment when compare to 0-hour pretreatment. Also, the fraction when compared to the standard drugs ketoprofen is as potent as standard drugs as shown in table 4.

Table 4: Effect of BF ANP on Carrageenan-induced paw edema in Wistar rats ( $n=6)$.

\begin{tabular}{|l|c|c|c|c|c|}
\hline \multirow{2}{*}{$\begin{array}{l}\text { Group: } \\
\text { Dose (mg/kg) }\end{array}$} & \multicolumn{5}{|c|}{ Paw diameter (cm) } \\
& Mh & $\mathbf{1 h}$ & $\mathbf{2 h}$ & $\mathbf{3 h}$ & $\mathbf{4 h}$ \\
\hline Normal Saline & $0.16 \pm 0.003$ & $0.18 \pm 0.02$ & $0.26 \pm 0.017$ & $0.3 \pm 0.028$ & $0.24 \pm 0.009$ \\
& & & & & \\
\hline BF ANP(160) & $0.16 \pm 0.006$ & $0.08 \pm 0.03^{\mathrm{b}}$ & $0.16 \pm 0.03^{\mathrm{a}}$ & $0.11 \pm 0.028^{\mathrm{b}}$ & $0.12 \pm 0.02^{\mathrm{c}}$ \\
\hline BF ANP(80) & $0,15 \pm 0.006$ & $0.09 \pm 0.02^{\mathrm{b}}$ & $0.12 \pm 0.03^{\mathrm{b}}$ & $0.1 \pm 0.028^{\mathrm{c}}$ & $0.12 \pm 0.017^{\mathrm{c}}$ \\
& & & & & \\
\hline BF ANP(40) & $0.15 \pm 0.004$ & $0.1 \pm 0.01^{\mathrm{b}}$ & $0.18 \pm 0.02^{\mathrm{a}}$ & $0.14 \pm 0.016^{\mathrm{c}}$ & $0.11 \pm 0.015^{\mathrm{c}}$ \\
\hline Ketoprofen(10) & $0.16 \pm 0.03$ & $0.07 \pm 0.003^{\mathrm{c}}$ & $0.09 \pm 0.01^{\mathrm{c}}$ & $0.096 \pm 0.014^{\mathrm{c}}$ & $0.09 \pm 0,017^{\mathrm{c}}$ \\
\hline
\end{tabular}

\subsection{Hot plate Test}

The BF ANP $(160,80.40 \mathrm{mg} / \mathrm{kg})$ significantly exerted protective effects on heat-induced pain in mice. Also a centrally acting analgesic drug, pentazocine $(10 \mathrm{mg} / \mathrm{kg})$, markedly increased pain latency time. However, their effect is more significant at the last $120 \mathrm{~min}$ and is dose-dependent at that time with more activity with $80 \mathrm{mg} / \mathrm{kg}(\mathrm{P} \leq 0.001)$ as shown in table 5 .

Table.5: Effect of BF ANP on hot plate response

\begin{tabular}{|l|c|c|c|c|}
\hline $\begin{array}{l}\text { Groups } \\
(\text { Dose: } \mathbf{m g} / \mathbf{k g})\end{array}$ & $\mathbf{3 0} \mathbf{~ m i n}$ & $\mathbf{6 0 m i n}$ & $\mathbf{9 0}$ min & $\mathbf{1 2 0}$ min \\
\hline & Mean \pm SE & Mean \pm SE & Mean \pm SE & Mean \pm SE \\
\hline Normal saline & $1.03^{ \pm} 0.077$ & $0.99 \pm 0.15$ & $1.31 \pm 0.16$ & $0.81 \pm 0.09$ \\
\hline BF ANP:160 & $1.08 \pm 0.069$ & $1.25 \pm 0.22$ & $1.33 \pm 0.16$ & $2.085 \pm 0.3^{\mathrm{a}}$ \\
\hline BF ANP:80 & $1.25 \pm 0.19$ & $1.72 \pm 0.2^{\mathrm{b}}$ & $1.92 \pm 0.20^{\mathrm{a}}$ & $2.29 \pm 0.28^{\mathrm{c}}$ \\
\hline BF ANP:40 & $2.31 \pm 0.57^{\mathrm{a}}$ & $2.24 \pm 0.44^{\mathrm{a}}$ & $2.9 \pm 0.84^{\mathrm{a}}$ & $3.33 \pm 0.71^{\mathrm{b}}$ \\
\hline Pentazocine10 & $1.3 \pm 0.17$ & $1.68 \pm 0.27^{\mathrm{a}}$ & $3.04 \pm 0.61^{\mathrm{a}}$ & $2.42 \pm 0.39^{\mathrm{b}}$ \\
\hline
\end{tabular}

\section{Discussion}

Pain management has been point out as one of the major challenges of healthcare systems over the world. Analgesics used for the clinical management of nociceptive pain traditionally follow the World Health Organization ladder, ranking from paracetamol, NSAIDs, and lastly opioids (Gronow et al., 2011). In this study, the main objective is to determine the role of the n-buthanol fraction of Acacia nilotica pods (BF ANP) in the suppression of pain and inflammation. It establishes the scientific basis and demonstrated the 
active portion of BF ANP on different analgesic models (acetic acid-induced writhing and hot plate method) and acute anti-inflammatory models (by carrageenan-induced paw edema). The different reactions observed in inflammatory responses cascade are therapeutic targets which anti-inflammatory agents including medicinal plants interfere with to inhibit inflammatory response usually evocated in such disorders including rheumatoid arthritis, infections, or injury (Iwueke et al.,2006). Inhibition of the synthesis of proinflammatory prostaglandins is one of such therapeutic targets to which some of the potent antiinflammatory agents of clinical relevance (e.g NSAIDs) own their activity (Viana et al., 1997). The antinociceptive and anti-inflammatory properties of NSAIDs are due to inhibiting COX enzymes implicated in the formation of prostaglandins. Prostaglandins are known as potent hyperalgesic mediators which modulate several sites along the nociceptive pathway and favor both transduction and transmission of nociceptive information which in turn leads to normalization of the increased pain threshold associated with inflammation. However, a full inflammatory response is sustained by prostanoids produced by both constitutive and inducible COX (Simmons et al., 2004). In this perspective, the BF ANP was studied for analgesic and anti-inflammatory potential in both peripheral (non-narcotic) and central narcotic type of pain model and carrageenan-induced paw edema. Ketoprofen and pentazocine were used as standards drugs. The phytochemicals screening of the BF ANP revealed the presence of flavonoids saponin, tannin, which have been demonstrated to have an analgesic effect on the acetic acid-induced writhing test (Shin et al., 1997; Calixto., 2000).

An acute toxicity study conducted by the method of Lorke 1983 revealed that BF ANP has a relative $\mathrm{LD}_{50}$ of $565 \mathrm{mg} / \mathrm{kg}$. During that toxicity study, we reported in some groups symptoms such as increased diuresis; weight loss occurred during the $72 \mathrm{~h}$ observation period which correlates with a previous report by (Manzo et al, 2019). Several studies demonstrated that the acetic acid-induced writhing test model is suitable to evaluate the peripheral type of analgesic action of herbal and other drugs (Dhara et al, 2000). In our study, the Acetic acid-induced writhing in mice shows that BF ANP possesses strong peripheral analgesic activity in all doses. The percentage inhibition is higher at high doses $(160 \mathrm{mg} / \mathrm{kg})$ about $94.4 \%$ and relatively low at lowest doses $71 \%$.when compare with standard drugs ketoprofen as control stipulating a dose-dependent effect of the plant fraction. The abdominal injection of acetic acid triggers the release of mediators of pain such as prostaglandins and other cytokines, meaning that the fraction may be acting by inhibiting the actions of cyclocoxygenase (COX) which is responsible for producing prostaglandins from arachidonic acids. Acetic acid causes an increase in the peritoneal fluid level of prostaglandins (PGE2 and PGF2 $\alpha$ ) and pain inflammation induced by capillary permeability (Deraedt et al, 1980). BF ANP significantly inhibited the abdominal constriction induced by acetic acid in mice and exhibited peripheral analgesic activity. Thus possibly is by those mechanisms that the $B F A N P$ inhibits the writhing produced by acetic acid. Some of the phytochemicals constituents of the fraction like flavonoids, saponins, and tannins have been demonstrated to have an analgesic effect on the acetic acid-induced writhing test (Shin et al., 1997, Calixto, 2000). Previous reports, however, show that the acetic acid-induced abdominal writhing test in mice is a nonspecific test that responds to both central and peripheral analgesia (Le Bar et al., 2001; Meotti et al., 2005, Malec et al., 2008). It is therefore used for screening analgesic properties. Ketoprofen produced significant pain inhibition. $B F A N P$ significantly reduced the writhing nociceptive behavior in mice indicating that BF ANP has either central or peripheral or both types of analgesic properties. The hot plate test is suitable for the evaluation of central analgesic activities. To clarify the analgesic effects of BF ANP the hot plate tests were performed. In Hot plate test, BF ANP prolonged the paw withdrawal latencies to thermal stimulation in mice. BF ANP, significantly increased paw withdrawal latencies 30, 60, 90,120minutes post-treatment, unlike the writhing test, thermally induced pain responds better to centrally acting agents (Chakraborty et $a l ., 2004)$ such as narcotics. In this model of pain, pentazocine which acts centrally significantly $(\mathrm{p}<0.05)$ increased the pain threshold in mice. The hot plate test involves the transmission of pain from the periphery via $C$ fibers to the spinal cord. Pain inhibition could be due to the prevention of $C$-fibres stimulation in the afferent nerves, which induced by the production of prostaglandin (Gupta et al, 2003) therefore BF ANP could be acting by inhibiting the transmission of pain via C fibers to the CNS whereby it's expressed its spinal analgesic effect. In the formalin test, $B F A N P$ showed significant analgesic properties. The first phase (early, acute phase) begins immediately ( $0-5 \mathrm{~min})$ after administration of formalin and coincide with neurogenic pain, and the second phase (late, tonic phase) usually beginning $15 \mathrm{~min}$ after formalin administration and it indicates inflammatory pain, BF ANP inhibited pain comparably to pentazocine in the early phase which has been proved to be sensitive to reversal by analgesics such as opioids. Formalin 
nociception is associated with tissue injury and is therefore believed to more closely resemble clinical pain when compared to other tests that use mechanical or thermal stimuli (dos Santos et al., 2006; Xie et al., 2005).In this test, the nociceptive response was in two distinct phases involving different mechanisms. The first phase (neurogenic pain) which began immediately after formalin injection resulted from the direct chemical stimulation of myelinated and unmyelinated nociceptive afferent fibers, mainly $\mathrm{C}$ fibers (Viegas $e t$ al., 2008). The second phase noted 20 - $30 \mathrm{~min}$ after formalin injection resulted from the release of inflammatory mediators in the peripheral tissues as well as facilitation of synaptic transmission at the spinal level (Hao et al., 2001). This later phase was reported to be sensitive to the action of the majority of NSAIDs (Hwang et al., 2008). Since the nociception in formalin test is most likely generated via the COX-1 as well as COX-2 pathways in the rat (Euchenhofer et al., 1998), ibuprofen rather than aspirin (irreversible COX-1) was taken as a positive control in this present formalin testing because of its non-selectivity in inhibiting COX enzyme. Previously, a study by (Daud et al., 2006)] showed that ibuprofen can decrease significantly the licking time of rats treated with formalin in their paws. The reduction of licking time, in both early and late phases after the administration of BF ANP was comparable to the effect of ibuprofen which stipulates the ability of this plant fraction to combat neurogenic and inflammatory pain. In this study, BF ANP inhibited the licking response of mice in both phases of the formalin test, suggesting that its antinociceptive effects could be through central mechanisms as compared to the standard control drugs (pentazocine) and peripheral. The present results suggest that the management of pain by this plant maybe by both peripheral and central pain inhibition or by inhibition of inflammatory mediators. and this may be attributed to some phytochemicals in that fraction like flavonoids, which have been shown to reduce the number of paw licking in the formalin test in rats (Calixto, 2000). The most widely used for the screening of new anti-inflammatory agents is the carrageenan-induced paw edema (Adomou, 2005) and is believed to be biphasic. In the early phase (1-2 h) the development of edema in the paw of the rat after the injection of carrageenan is due to the release of histamine, serotonin, and prostaglandin-like substances. The late phase is sustained by prostaglandin release and mediated by bradykinin, leukotrienes, polymorphonuclear cells, and prostaglandins produced by tissue macrophages (Vittalrao, et al, 2011) (Antonio et al, 1998). In this study Carrageenan injection resulted in paw volume increase which was inhibited significantly by BF ANP in all doses groups $40 \mathrm{mg} / \mathrm{kg} ; 80 \mathrm{mg} / \mathrm{kg}$ and $160 \mathrm{mg} / \mathrm{kg}$ from 1 - 4 h post carrageenan injection and Ketoprofen significantly reduced inflammation throughout the 4 hours post-injection. The observed responses stipulate that BF ANP possessed anti-inflammatory activities in both the early and late phase of inflammation when compared to the standard NSAID drugs Ketoprofen. In line with many studies that have shown the antiinflammatory potential of flavonoids(Rauf et al,2016). Similarly in this study, the anti-inflammatory activity of BF ANP observed may be likely been attributed to flavonoids contained in the active fraction of the plant extract. Furthermore, The BF ANP was mostly active in the last phase of the carrageenan response phase. Carrageenan injection causes an increase in paw volume $1 \mathrm{~h}$ after carrageenan injection and maximal paw volumes are attained $4 \mathrm{~h}$ after injection. Several studies demonstrated that the early phase of edema resulting from carrageenan injection commonly corresponds with the early exudative stage of inflammation, which is an important process in inflammatory pathology (Gupta et al., 2006, Lee et al., 2006). The second phase is reportedly due to the liberation of bradykinin, prostaglandins, and kinins in injected paw tissue accompanied by leukocyte migration (Pinheiro and Calixto, 2002). Although the cyclooxygenase and lipoxygenase pathways are both involved in the inflammatory process, the inhibition of cyclooxygenase is more effective in inhibiting carrageenan-induced inflammation than lipoxygenase inhibitors (Giuliano and Warner, 2002). Taken all together, our results suggest that BF ANP suppresses the first phase and second of carrageenan-induced paw edema, thus, confirming an NSAID-like property. The n-buthanol fraction of Acacia nilotica pods at tested doses was shown to possess antinociceptive activity evident in all the nociceptive models. The fraction also shows strong significant peripheral and central analgesic and antiinflammatory properties and this is well defined for various non-steroidal anti-inflammatory drugs particularly the salicylates and their derivatives since the cyclo-oxygenase enzymes which leads to the production of prostanoids is usually inhibited. It is therefore evident that the fraction behaves similar to NSAIDs in this study which correlate well with the traditional application of the plant in pain and inflammatory condition as confirmed by the previous preliminary work carried by ( Dafallah and AlMustapha;1996) shown the anti-inflammatory, analgesic and antipyretic properties of aqueous extract of the plant. The flavonoids, saponin, and tannin might be responsible in part for the observed effect because 
flavonoids are known to inhibit the metabolism of arachidonic acid whereas the tannins inhibit the synthesis of prostaglandins (Davis et al., 1984).

\section{Conclusions}

The present study showed that $\mathrm{n}$ - buthanol fraction of Acacia nilotica pods (BF NP) possess both central and peripheral analgesic activity These results suggested that the fraction may have NSAIDs-like activity through the peripheral mechanism and central analgesic activities via opioids receptors. The result of the experiments appears to suggest that the fraction is effective in alleviating peripheral and central pain. In the acetic acid-induced writhing model the constrictions induced by acetic acid in mice result from an acute inflammatory reaction with the production of PGE2 and PGF2 $\alpha$ in the peritoneal fluids (Vyas et al., 2008). Therefore it is likely that the fraction might suppress the formation of these substances or antagonizing their action for its analgesic activity. The peripheral mechanism of the fraction may be via inhibition of cyclooxygenase and/or lipoxygenases (and other inflammatory mediators) while the central analgesic action may be via the inhibition of the central pain receptors. This hypothesis aligns with those of (Koster et al., 1959) who have postulated that acetic acid-induced writhing and hot plats test methods are useful techniques for the evaluation of the central and peripheral analgesic activity. Also, the fraction possesses antiinflammatory properties and these activities may be attributed to flavonoids present in this n-buthanol portion because flavonoids are known for their anti-inflammatory antalgic and vasoprotective properties and this is because they influenced arachidonic acid metabolism (Evans,2002), one important mechanism is inhibition of eicosanoid acid generated enzymes including A2, COX1, Lipoxigenase thereby reducing the concentration of prostaglandins and leukotrienes, thus validating the traditional use of this plant in pain management and inflammation.

\section{Declaration}

\subsection{Ethical approval and consent to participate}

The research has been conducted under the approval of animal ethical committee Ahmadu Bello University Zaria

\subsection{Consent to publication}

'Not Applicable' in this section.

\subsection{Availability of data and materials}

Data and materials are available on demand

\subsection{Funding}

This work did not receive any specific grant from funding agencies in the public, commercial, or not-for-profit sectors.

\subsection{Authors' contributions}

Dr M.T.M S and Prof A.Y performed the research and wrote the paper; Dr Y. T designed the work, Prof R.A.M provided language editing. All authors have read and approved the manuscript

\subsection{Competing interests}

All authors declare no competing interests.

\subsection{Acknowledgements}

Authors wish to acknowledge the Ahmadu Bello University laboratory technician in facilitating research

\section{References}

1. Adomou, A.C., 2005. Vegetation patterns and environmental gradients in Benin: implications for biogeography and conservation [Ph. D. thesis]. Wageningen, the Netherlands: University of Wageningen.

2. Antonio, M.A. and A.R.M. Souza Brito, 1998. Oral anti-inflammatory and anti-ulcerogenic activities of a hydroalcoholic extract and partitioned fractions of Turnera ulmifolia (Turneraceae). J. Ethnopharmacol., 61: 215-228

3. Aiyelero, O.M., Z.G. Ibrahim, and A. H.Yaro, 2009. Analgesic and anti-inflammatory properties of the methanol leaf extract of Ficus ingens (moraceae) in rodents. Nigerian Journal of Pharmacological Sciences. Vol. 8 No. 2, P. $79-86$ 
4. Calixto, J.B., 2000. Efficacy, safety, quality control, marketing and regulatory guidelines for herbal medicines (phytotherapeutic agents). Brazilian Journal of medical and Biological research, 33(2), pp.179-189.

5. Chakraborty A, R.K.B, Devi, S, Rita, K. Sharatchandra, T.I Singh, 2004.Preliminary studies on anti-inflammatory and analgesic activities of Spilanthes acmella in experimental animal models. International. Journal. Pharmacology.36: 148-150

6. Dafallah.A and Z. Al-Mustapha, 1996. Investigation of the anti-inflammatory activity of Acacia nilotica and Hibiscus sabdariffa.American Journal of Chinese Medicine, 24, 263-269.

7. Davis, P, P.J.Bayley, M..M. Goldenberg, and A.W.Ford-Hutchinson, 1984.The role of arachidonic acid oxygenation products in pain and inflammation.Annual Review of Immunology; 2:335-357

8. Deraedt, R., S. Jouquey, F. Delevallee and M. Flahaut, 1980. Release of prostaglandins E and F in an algogenic reaction and its inhibition. Eur. J. Pharmacol., 61: 17-24

9. Dhara, A.K., V. Suba, T. Sen, S. Pal and A.K.N. Chaudhuri, 2000. Preliminary studies on the antiinflammatory and analgesic activity of the methanolic fraction of the root extract of Tragia involucrata Linn. J. Ethnopharmacol., 72: 265-268

10. Dos Santos MD, M. Camila, N.P. Lopes, G.E.P de Souza 2006.Evaluation of the anti-inflammatory, analgesic, and antipyretic activities of the natural polyphenol chlorogenic acid. Biology. Pharmacology. 29:2236-2240.

11. Euchenhofer, C., Maihöfner, C., Brune, K., Tegeder, I. and Geisslinger, G., 1998. Differential effect of selective cyclooxygenase-2 (COX-2) inhibitor NS 398 and diclofenac on formalin-induced nociception in the rat. Neuroscience letters, 248(1), pp.25-28.

12. Evans. W.C. 2002 Trease and Evans Pharmacognosy. $15^{\text {th }}$ Edn, Balliera Tindall, London, ESBN-10; 0702026174

13. Giuliano F,and T.D Warner 2002. Origins of Prostaglandin E2: Involvements of Cyclooxygenase (COX)-1 and COX-2 in Human and Rat Systems. Journal. Therapy. 303: 1001-1006.

Pharmacology. Experimental.

14. Gronow, D.W., 2011. The place of pharmacological treatment of chronic pain. Anaesthesia \& Intensive Care Medicine, 12(2), pp.39-41.

15. Gupta M, U.K Mazumder, P. Gomathi, V.T Selvan 2006.Anti-inflammatory evaluation of leaves of Plumeria acuminate. British Medical Journal. Compl. Alter. Medicine. 6: 36-41

16. Gupta, M., U.K. Mazumder, R.S. Kumar and T.S. Kumar, 2003. Studies on anti-inflammatory, analgesic, and antipyretic properties of methanol extract of Caesalpinia bonducella leaves in experimental animal models. Iran. J. Pharmacol. Therapeutics, 2: 30-34

17. Hao S, O, Takahata, and H .Iwasaki 2001. Antinociceptive interaction between spinal clonidine and lidocaine in the rat formalin test: anisobolographic analysis. Anesthesia. Analgesia. 92: 733-738

18. Henschke N, Kamper SJ, Maher CG, 2015. The epidemiology and economic consequences of pain. Mayo Clinic Proceedings. Elsevier.

19. Hwang, H.J., Kim, P., Kim, C.J., Lee, H.J., Shim, I., Yin, C.S., Yang, Y. and Hahm, D.H., 2008. Antinociceptive effect of amygdalin isolated from Prunus armeniaca on formalin-induced pain in rats. Biological and Pharmaceutical Bulletin, 31(8), pp.1559-1564.

20. Iwueke, A.V., Nwodo, O.F.C. and Okoli, C.O., 2006. Evaluation of the anti-inflammatory and analgesic activities of Vitex doniana leaves. African Journal of Biotechnology, 5(20), p.1929.

21. Koster, R., M. Anderson and E.J. Debeer, 1959. Acetic acid analgesic screening. Fed Proced. 18: 418-420

22. Kumar, K.H. and Elavarasi, P., 2016. Definition of pain and classification of pain disorders. Journal of Advanced Clinical and Research Insights, 3(3), pp.87-90.

23. Kumar, V., A.K. Abbas, and J.C. Aster, Robbins basic pathology e-book. 2017: Elsevier Health Sciences

24. Le Bars, D., Gozariu, M. and Cadden, S.W., 2001. Animal models of nociception. Pharmacological reviews, 53(4), pp.597-652.

25. Lee JY, Y.W.Jang, H.S Kang, H.Moon, S.S. Sim, C.J. Kim 2006. Anti inflammatory action of Phenolic Compounds from Gastrodia elata Root. Arch. Pharmacology 29: 849-858. 
26. Lompo-Ouedraogo, Z., Van Der Heide, D., Van Der Beek, E. M., Swarts, H. J., Mattheij, J. A., Sawadogo, L. (2004). Effect of aqueous extract of Acacia nilotica ssp adansonii on milk production and prolactin release in the rat. Journal of Endocrinology, Vol:182(2), P: 257-266.

27. Lorke, D. 1983. A new approach to acute toxicity testing. Archives of toxicology, 54:275-287.

28. Malec D, M. Mandryk, S. Fidecka 2008. Interaction of memantine and ketamine morphine- and pentazocine-induced antinociception in mice. Pharmacology. Rev 60: 149-155.

29. Manzo, L. M., Moussa, I., Ikhiri, K., \& Yu, L. (2019). Toxicity studies of Acacia nilotica (L.): A review of the published scientific literature. Journal of Herbmed Pharmacology, 8(3), 163-172.

30. Meotti F.C, A.P. Luiz, M.G. Pizzolatti, C.A.L. Kassuya, J.B. Calixto, A.R.S.Santos 2005. Analysis of the antinociceptive effect of the flavonoid myricitrin. Evidence for a role of the L-arginine-nitric oxide and proteinkinase C pathways. JPET 10: 1124-1158

31. Ojewole, J.A.O. 2006. Analgesic, Antiinflammatory, and Hypoglycaemic Effects of Ethanol Extract of Zingiber officinale (Roscoe) Rhizomes (Zingiberaceae) in Mice and Rats. Phytotherapy. Res. 20, 764-7

32. Pinheiro RM and J.B. Calixto 2002. Effect of the selective COX-2 inhibitors, celecoxib, and rofecoxib, in rat acute models of inflammation. Inflammation Res. 51: 603

33. Rauf, A., Uddin, G., Siddiqui, B. S., Khan, H., Shah, S. U. A., Hadda, T. B. \& Khan, A. 2016. Antinociceptive and anti-inflammatory activities of flavonoids isolated from Pistacia integerrima galls. Complementary therapies in medicine, 25, 132-138.

34. Schug, S.A., Garrett, W.R. and Gillespie, G., 2003. Opioid and non-opioid analgesics. Best Practice \& Research Clinical Anaesthesiology, 17(1), pp.91-110.

35. Shin, Y.H., S.C.Kim, J.W . Han, D.H Kim, S.S. Han, D.H Shin,.and S.Y. Nah.1997.Study on ginseng protopanaxadiol and saponins-induced antinociception.Korean Physiology and Pharmacology,2:143-149.

36. Simmons, D.L., Botting, R.M. and Hla, T., 2004. Cyclooxygenase isozymes: the biology of prostaglandin synthesis and inhibition. Pharmacological Reviews, 56(3), pp.387-437.

37. Stanton-Hicks, M., Jänig, W., Hassenbusch, S.A., Haddox, J.D., Boas, R. and Wilson, P., 1995. Reflex sympathetic dystrophy: changing concepts and taxonomy. Pain, 63(1), pp.127-133.

38. Taber, R.I., D.D. Greenhouse, J. K. Rendel, and S.Irwin, 1969. Agonist and antagonistinteractions of opioids on acetic acid-induced abdominal stretching in mice. J. Pharmacol. Exp. Therap., 169: 29-37.

39. Tamrat, Y., Nedi, T., Assefa, S., Teklehaymanot, T. and Shibeshi, W., 2017. Anti-inflammatory and analgesic activities of solvent fractions of the leaves of Moringa stenopetala Bak. (Moringaceae) in mice models. BMC complementary and alternative medicine, 17(1), pp.1-10.

40. Trease, G.E. and M.C.Evans, 1983. Textbook of pharmacognosy. 12th ed. Tindall, London. $\quad$ Pp: 322-383.

41. Turner, R. A.,1965.Screening methods in pharmacology.Academic Press.London.P.100

42. Viana,G.S.B.,M.A.M.Bandeira,L.C.Moura,MVP.Filho-Souza,F.J.A.Matos,R.A.Ribeiro, 1997.Analgesic and Anti-inflammatory effect of tannin, fraction from Myracrodroum, ururdeuva.Fr.All.Phythera.Res.11;118-122.

43. Viegas, C., S. Alexandre-Moreira, M. Fraga, E.J. Barreiro, V.S. Bolzani, A.L.P. deiranda, 2008. Antinociceptive profile of 2,3,6-trisubstituted piperidine alkaloids: 3-o-acetyl-spectaline and semi-synthetic derivative of (-)-spectaline. Chemical. $\quad$ Pharmacology. Bulletin. 56: 407-412.

44. Vittalrao, M.A., T. Shanbhag, K.M. Kumari, K.L. Bairy, and S. Shenoy, 2011. Evaluation of antiinflammatory and analgesic activities of alcoholic extract of Kaempferia galanga in rats. Indian J. Physiol. Pharmacol., 55: 13-24

45. Vyas,S. R., P.Agrawal,. P. Solanki, and P.Trivedi, 2008.Analgesic and anti-inflammatory act.ivities of Trigonella foenum-Graecum (seeds) Extract.Acta poloniae Pharmaceutica-Drugs Reseach; Vol.65 No4 pp473-476.

46. World Health Organization, 2012. Persisting pain in children package: WHO guidelines on the pharmacological treatment of persisting pain in children with medical illnesses.

47. Xie Y.F., J. Wang, F.Q.Huo, H. Jia, J.S. Tang, 2005. Validation of a simple automated movement detection system for formalin test in rats1 Acta.Pharmacology Sinica 26: 39-45. 
48. Yerima, M., M.G. Magaji, A.H.Yaro, Y .Tanko, and M. Mohammed, 2009. Analgesic and antiinflammatory activities of the methanolic leaves extract of securinega virosa (euphorbiaceae). Nigerian Journal Pharmacological Sciences. Vol. 8 No. 1. P. $47 \quad-53$.

49. Yoon SB, Lee YJ, Park SK, Kim HC, Bae H, Kim HM, Ko SG, Choi HY, Oh MS, Park W,2009. Anti-inflammatory effects of Scutellaria baicalensis water extract on LPS-activated RAW 264.7 macrophages. J Ethnopharmacol. ; Vol 125: P.286-290 